\title{
Pengaruh Green Intellectual Capital Terhadap Keunggulan Kompetitif Dengan Pemediasi Green Human Resource Management
}

\author{
Qurota A'yuni ${ }^{1}$, Muafi ${ }^{2}$ \\ ${ }^{2}$ Correspondence Author: muafi@uii.ac.id \\ ${ }^{1}$ Universitas Islam Indonesia, Indonesia \\ ${ }^{2}$ Universitas Islam Indonesia, Indonesia
}

INDEXING
Keywords:

Management;

Green HRM:

Green Intellectual

Capital;

Kata kunci:

Manajemen;

Green HRM;

Green Intellectual

Capital;

\begin{abstract}
This study examines the role of green human resource management in mediating the influence of green intellectual capital on competitive advantage. The type of this study is quantitative research wich is carried out by distributing questionnaire to all Batik MSMEs owners in Batik Tulis Kebon Indah Group with number of 169 MSMEs. The sampling technique is conducted using purposive sampling method, with 136 respondents obtained. The hypotheses proposed in this study are tested using regression analysis with Partial Least Square with SmartPLS 3.0 application. The result of this study shows that green human resource management has a role in mediating the influence of green intellectual capital on competitive advantage of natural dyes-Batik MSMEs in Kebon Indah Group.
\end{abstract}

\section{ABSTRAK}

Penelitian ini menguji peran green human resource management dalam memediasi pengaruh green intellectual capital terhadap keunggulan kompetitif. Penelitian kuantitatif dilakukan dengan menyebarkan kuisioner kepada seluruh pemilik UKM batik di Paguyuban Batik Tulis Kebon Indah sebanyak 169 UKM. Dengan metode purposive sampling, sampel akhir yang memenuhi kriteria pengujian sejumlah 136 responden. Pengujian hipotesis yang diajukan dilakukan dengan analisis regresi Partial Least Square dengan bantuan aplikasi SmartPLS versi 3.0. Hasil penelitian menunjukan bahwa green human resource management berperan dalam memediasi pengaruh green intellectual capital terhadap keunggulan kompetitif pada UKM Batik warna alam di Paguyuban Kebon Indah.

\section{ARTICLE HISTORY}

Received: 2020-06-14 Revised: 2020-08-05 Accepted: 2020-08-28

\section{PENDAHULUAN}

Indonesia dikenal sebagai paru-paru dunia. Sebagaimana teknologi,trend pada perindustrian di Indonesia saat ini juga mengalami pergerakan yang cepat. Saat ini, perhatian para pengusaha dan akademisi sangat tinggi terhadap praktek green business. Hal ini terjadi karena kesadaran masyarakat yang semakin tinggi terhadap dampak lingkungan yang mereka hasilkan. Berdasarkan green industry report pada 2014, hasil survey menemukan bahwa 55\% konsumen dari 60 negara ingin membayar lebih untuk barangbarang yang berasal dari perusahaan yang sadar lingkungan. Pada 2013, sebuah study mengklaim bahwa setidaknya $71 \%$ orang amerika mempertimbangkan factor lingkungan ketika berbelanja (Kim, 2016) Praktek green business saat ini telah berkembang menjadi greening area fungsionalnya, salah satunya yaitu pada green human resource management (Yong, et al., 2019) .

Untuk dapat bertahan ditengah-tengah pergerakan trend green saat ini, sebuah organisasi harus memiliki kemampuan untuk bersaing dengan memiliki keunggulan dalam berkompetisi. Pada era ekonomi baru, asset tak berwujud menjadi salah satu penentu penting untuk mendapatkan keunggulan kompetitif, dan pada era ekoonomi pengetahuan, modal intelektual selalu lebih besar dari modal keuangan (Chen, 2008). Dari sudut pandang 
organisasi, mengembangkan asset intangible yang kuat akan memberikan peluang pada organisasi untuk meningkatkan keunggulan kompetitif (Yusoff, et al., 2019). Green intellectual capital merupakan modal intelektual yang berorientasi pada lingkungan, hal ini merupakan investasi yang efektif, namun, di Indonesia, intellectual capital belum mendapatkan perhatian lebih.

Dalam dunia bisnis, beberapa perusahaan lokal di Indonesia telah banyak menaruh perhatian pada bisnis hijau. Salah satunya yaitu organisasi Batik yang merupakan kerajinan asal Indonesia yang saat ini sudah popular dimata dunia. Batik Tulis Kebon Indah merupakan sebuah organisasi berbentuk Paguyuban yang memproduksi batik tulis khusus pewarna alam yang telah dikenal secara internasional. Paguyuban batik ini telah terbentuk sejak 2006 dan hingga sekarang dapat tetap bertahan dengan hanya menggunakan bahan alami. Menurut Mandip (2012), green HRM merupakan manifesto yang dapat membantu menciptakan green workforce yang mampu memahami dan menghargai budaya green dalam organisasi (Rohilla, 2017). Sebagaimana yang telah ditunjukkan oleh sejumlah besar jurnal terkemuka sebelumnya (Muller-Camen et al., 2010; Renwick et al., 2012; Taylor et al., 2012; Andersson et al., 2013; Kramar and Mariappanadar, 2015), karyawan dan Manajemen Sumber Daya Manusia (SDM) di suatu perusahaan memiliki peran dalam usaha "greening" pada sebuah organisasi (Pinzone, et al., 2016). Oleh karena itu, penelitian ini dilakukan untuk menguji dan menganalisis pengaruh green intellectual capital terhadap keunggulan kompetitif dengan pemediasi green human resource management, dengan melakukan survey pada pemilik UKM barik pewarna alam di Paguyuban Kebon Indah.

\section{TINJAUAN PUSTAKA}

Intellectual capital merupakan asset intangible pada sebuah perusahaan termasuk pengetahuan, kapabilitas karyawan, teknologi, pengalaman, dan kemampuan dalam mengimplementasi inovasi agar tujuan perusahaan apat tercapai (Huang \& Kung, 2011), yang mana telah menjadi lebih penting daripada asset tangible dalam ekonomi berbasis pengetahuan. Menurut Hsu dan Fang (2009), konsep intellectual capital adalah total kapabilitas, pengetahuan, budaya, strategi, proses, property intelektual, dan jaringan relasional pada perusahaan yang manciptakan nilai atau keunggulan kompetitif dan membantu perusahaan untuk mancapai tujuannya (Castro, et al., 2011). Intellectual capital dengan lingkungan alam (natural environment) disebut dengan green Intellectual capital (Yusoff, et al., 2019). Berdasarkan pengklasifikasian IC yang dilakukan oleh Bontis (1999) dan Johnson (1999), Chen (2008) mengklasifikasikan GIC menjadi green human capital, green structural capital, dan green relational capital.

Human capital didefinisikan sebagai penyajian akhir dari pengetahuan, keahlian, inovasi, dan kemampuan karyawan untuk mencapai tujuan (Dzinkowski, 2000). Karakteristik kunci dari human capital yaitu tidak dapat dimiliki oleh perusahaan (Castro, et al., 2011). Human capital tertanam dalam diri karyawan dan bukan dalam organisasi (Chen, 2008).

Berbeda dengan human capital, structural capital atau organizational capital tertanam dalam organisasi, sehingga tidak akan hilang bersamaan dengan perginya karyawan. Chen (2008), mendefinisikan Green structural capital sebagai persediaan kapabilitas organisasional, komitmen organisasional, sistem manajemen pengetahauan, sistem rewards, teknologi sistem informasi, database, mekanisme manajerial, proses operasi, filosofi manajerial, budaya organisasional, imej perusahaan, hak paten, hak cipta, 
dan merek dagang, dll. Tentang melindungi lingkungan atau green innovation pada perusahaan. Green relationship capital didefinisikan sebagai total hubungan interaktif perusahaan dengan customer, supplier, anggota jarngan, dan patner tentang manajemen lingkungan dan green innovation, yang memungkinkannya untuk menciptakan kekayaan dan memperoleh keunggulan kompetitif (Yong, et al., 2019).

HRM (Human Resource Management) atau biasa disebut Sumber Daya Manusia (SDM) merupakan beberapa kebijakan dan praktik yang diperlukan seseorang yang menjalankan aspek orang atau perekrutan, penyaringan, pelatihan, pengimbalan, dan pembaruan (Astuti \& Wahyuni, 2018). Green HRM merupakan pengembangan dari HRM, dengan menambahkan aspek lingkungan. Green HRM dapat dipandang sebagai kegiatan SDM yang utuh dan terintegrasi yang terlibat dalam pengembangan, implementasi dan pemeliharaan berkelanjutan pada suatu sistem, yang memastikan karyawan suatu organisasi dapat melakukan secara efektif (Sudin \& Saad, 2018), dan bertujuan untuk membuat karyawan organisasi menjadi hijau untuk kepentingan individu, masyarakat, lingkungan, dan bisnis (Jirawuttinunt, 2018).

GHRM terdiri dari seluruh praktik SDM yaitu: analisis dan deskripsi posisi pekerjaan, rekrutmen dan seleksi, pelatihan dan pengembangan, kinerja dan penilaian, serta reward (Yong, et al., 2019), yang dikenal sebagai alat penting untuk menyelaraskan staf dengan strategi lingkungan organisasi di bidang manajemen sumber daya manusia (Jirawuttinunt, 2018). Beberapa peneliti telah mendefinisikan green human resource management dalam beberapa literaturnya sebagai integrasi manajemen lingkungan perusahaan ke dalam manajemen sumber daya manusia (Renwick, et al., 2013; Renwick, et al., 2008; Jabbour, et al., 2010; Arulrajah, et al., 2015).

Terdapat beberapa perbedaan karakteristik antara Human Resouce Management dan Green Human resource Management, perbedaan mendasar antara HRM dan GHRM terletak di keberlanjutan dan persepsi orientasi lingkungan pada GHRM. Ketika karakteristik seperti perfection, competitive advantage, dan kepemimpinan inspector menonjol di HRM, yang menonjol di pada GHRM adalah keberlangsungan lingkungan dan kepemimpinan evolusioner yang mana dapat membantu mengembangkan dan mengimplementasikan kebijakan kebijakan terkait lingkungan (Aykan, 2017). Pada penelitian ini green HRM akan diukur berdasarkan: Green analysis and description of jobs, Green recruitment, Green performance assessment, Green rewards, Green selection, dan Green training (Jabbour, 2011; Yusliza, 2016; Yong et al, 2019).

Dalam bidang HRM, beberapa penelitian terdahulu telah menggarisbawahi pengaruh praktek HR dalam mengembangkan beberapa aspek IC, namun Kong dan Thomson (2009) memberi pandangan yang kontradiktif bahwa IC, HRM stratejik, dan konsep HRM berhubungan erat, dan IC harus menjadi kekuatan pendorong pada hubungan tersebut (Yong, et al., 2019). Yong et al. (2019), pada penelitiannya mengatakan bahwa terdapat relasi positif antara green intellectual capital (green human capital, green structural capital dan green relational capital) dengan green human resource management. Sudin dan Saad (2018) mengatakan bahwa green HRM berkorelasi positif dengan green IC. Dari beberapa penelitian sebelumnya juga dapat disimpulkan bahwa terdapat relasi yang positif antara green intellectual capital dengan green human resource management (Heidi Olander et al, 2016; Akbari et al, 2013; Yang dan Carol, 2014; Budiarti, 2017).

Saat ini, komunitas bisnis mengadopsi sistem manajemen lingkungan yang pada gilirannya merupakan alat untuk memberikan keunggulan kompetitif dan membantu 
mengendalikan dampak perusahaan terhadap lingkungan. Praktik green HRM dapat mempertahankan karyawan yang baik dalam organisasi, dengan mengurangi biaya replacement (Rohilla, 2017). Keunggulan kompetitif perusahaan berkaitan dengan kemampuan perusahaan untuk memenangkan persaingan pasar melalui cara-cara yang khas dan tidak dimiliki oleh perusahaan pesaing.

Penelitian sebelumnya yang dilakukan oleh Khanna and Anton, 2002; Christmann, 2000; Shrivastava, 1995, telah menemukan bahwa Organisasi dapat mengambil manfaat dari mengadopsi intervensi manajemen lingkungan, karena kegiatan pro-lingkungan memiliki hubungan positif dengan branding perusahaan, citra publik, peluang pemasaran, peningkatan penjualan, penghematan biaya potensial dan keunggulan kompetitif (Mishra, 2017). Dari penelitian yang dilakukan oleh Sancho et al. (2018), Khatri (2000), Mishra (2017), Yusliza et al. (2019), Zaid (2018) menunjukan bahwa GHRM memiliki peran penting bagi perusahaan agar tercipta perusahaan dengan keunggulan kompetitif.

Porter dan van der Linde (1995), Shrivastava (1995), dan Berry dan Rondinelli (1998) berpendapat bahwa perusahaan yang melibatkan manajemen lingkungan perusahaan dan green innovation secara aktif tidak hanya dapat mengurangi limbah produksi dan meningkatkan produktivitas, tetapi juga meningkatkan citra perusahaan, menjual pengetahuan dan layanan perlindungan lingkungan, mengembangkan pasar baru dan pada akhirnya akan mendapatkan keunggulan kompetitif. Oleh karena itu, terlibat dalam manajemen lingkungan dan green innovation secara aktif memiliki pengaruh positif terhadap keunggulan kompetitif perusahaan.

Berdasarkan sudut pandang sumber daya dari organisasi, mengembangkan intangibles yang kuat dapat memberikan peluang bagi organisasi untuk meningkatkan kinerja bisnis, mendapatkan keunggulan kompetitif, inovasi dan sebagai keberlangsungan hidup organisasi (Yusoff, et al., 2019). Namun, tidak ada penelitian yang mengeksplorasi apakah modal intelektual tentang manajemen lingkungan atau inovasi hijau memiliki efek positif pada keunggulan kompetitif perusahaan (Chen, 2008).

Mazzi et al. (2016), mengungkapkan bahwa atribut karyawan adalah aset yang tak ternilai dalam mencapai green HRM yang sukses. Atribut-atribut ini tidak dimiliki oleh organisasi dan tidak dapat ditiru. Karena keunikan ini, atribut ini adalah bentuk keunggulan kompetitif bagi suatu organisasi (Yong, et al., 2019). Huang dan Kung (2011) melakukan penelitian yang memberikan hasil bahwa kesadaran lingkungan secara tidak langsung berpengaruh terhadap keunggulan kompetitif. Pengaruh kesadaran lingkungan terhadap keunggulan kompetitif terjadi melalui investasi atau mediasi oleh green intellectual capital. Chalal dan Bakshi (2014) mengungkapkan bahwa Intellectual capital membangun inovasi yang memiliki kecenderungan untuk mencapai atau meraih keunggulan kompetitif. Santosh Raj (2017) mengatakan bahwa Green HRM dapat digunakan sebagai alat untuk keunggulan kompetitif mereka. Chen (2008) mengungkapkan bahwa green IC memiliki dampak positif terhadap keunggulan kompetitif perusahaan. Ini artinya, green intangible capital berguna bagi perusahaan untuk meningkatkan green competitive advantage nya (Chen dan Chang, 2013).

Hipotesis: Green human resource management dapat memediasi pengaruh green intellectual capital terhadap keunggulan kompetitif. 


\section{METODE PENELITIAN}

Populasi dalam penelitian ini adalah seluruh pemilik UKM Batik di paguyuban Batik pewarna alam Kebon Indah, Klaten sebanyak 169 UKM yang terbagi dalam 5 kelompok wilayah. Sedangkan untuk pengambilan sampel, penelitian ini menggunakan teknik purposive sampling dengan kriteria responden memproduksi dan menjual produk Batik diluar permintaan dari paguyuban dan responden telah bergabung bersama paguyuban selama 1 tahun atau lebih. Jumlah angket kuisioner yang dibagikan adalah 169 buah kuisioner dan kembali sejumlah 169 kuisioner. Dari kriteria yang diajukan, terdapat 12 kuisioner yang tidak berisi data diri, 27 responden tidak memproduksi batik diluar permintaan dari Paguyuban, dan 1 responden memiliki masa bergabung dengan paguyuban kurang dari 1 tahun sehingga sampel total yang dijadikan objek penelitian berjumlah 136 kuisioner.

Pada penelitian ini, peneliti menggunakan data primer dengan kuisioner. Dalam kuisioner yang dibagikan, peneliti menggunakan pengukuran dengan skala Likert yang terdiri dari 5 poin skala Likert. Untuk pengujian hipotesis, akan dilakukan dengan analisis Partial Least Squares (PLS) menggunakan bantuan software SmartPLS versi 3.0. Analisis PLS ini digunakan untuk mengetahui pengaruh langsung maupun pengaruh tidak langsung variable eksogen terhadap variable endogen. Pengujian hipotesis dilakukan dengan level keyakinan $95 \%(\alpha=0.05)$.

\section{HASIL DAN PEMBAHASAN}

\section{Analisis deskriptif}

Teknik analisis statistik deskriptif adalah statistik yang digunakan untuk menganalisa data dengan cara mendeskripsikan atau menggambarkan data yang telah terkumpul sebagaimana adanya tanpa bermaksud membuat kesimpulan yang berlaku umum atau generalisasi (Sugiyono, 2014). Hasil analisis deskriptif menggambarkan bahwa sebagian besar responden berusia antara 26 - 45 tahun (47\%) dan usia 46 - 65 tahun dengan beda $1 \%$ saja (46\%). Menurut WHO, usia dibawah 65 tahun masih dianggap sebagai usia muda atau dewasa karena masih banyak aktivitas yang dapat dilakukan oleh manusia dalam rentang usia tersebut. Oleh karena itu, anggota lansia pada Paguyuban dianggap masih produktif dan tetap dapat dijadikan responden dalam penelitian ini.

Hasil analisis juga menunjukan bahwa sebagian besar responden telah tergabung dalam Paguyuban Batik Tulis Kebon indah selama 5-10 tahun (74\%). Pada masa bergabung tersebut, para pemilik UKM sudah dapat dikatakan dapat memahami sistem yang berlaku di Paguyuban tersebut sehingga dianggap memenuhi kualifikasi sebagai responden. Penilaian responden pada tiap variabel yang diajukan pada penelitian ini juga termasuk pada kriteria yang tinggi baik untuk variabel green intellectual capital, green human resource management, maupun keunggulan kompetitif, yaitu dengan total rata-rata nilai pada tiap variabel berkisar antara 3.41 sampai dengan 4.20.

\section{Evaluasi outer model}

Model pada penelitian ini dikembangkan dengan menyertakan second order construct untuk green intellectual capital. Kemudian first order construct akan diuji berdasarkan validitas dan reliabilitas second order construct. Pada hasil uji PLS menggunakan SmartPLS. Pada estimasi pertama, terdapat 2 indikator yang memiliki nilai loading $<0.5$ 
(GHRM14 dan GHC4), sehingga 2 indikator tersebut di drop dari model, kemudian dilakukan estimasi ulang pada model. Tabel.1 menunjukan bahwa seluruh nilai loading pada uji convergent validity lebih dari 0.7. Artinya, model pada penelitian ini telah memiliki convergent validity yang baik. Selanjutnya, akan diuji apakah indikator pada penelitian ini telah tepat digunakan untuk mengukur variabel laten nya dengan uji discriminant validity. Dapat dilihat pada tabel nilai cross loading (Tabel 2) bahwa setiap indikator telah tepat penggunaannya untuk mengukur variabel latennya.

Untuk uji reliabilitas, dapat dilihat pada Tabel.3 bahwa seluruh nilai pada kolom Cornbatch's Alpha $>0.7$ dengan nilai AVE seluruhnya $>0.5$. Artinya, seluruh item reliabel dan dapat dihunakan untuk uji hipotesis.

\section{Evaluasi inner model \\ R-Square}

Tabel.4, menunjukan bahwa nilai yang diperoleh variabel CA (keunggulan kompetitif) sebesar 0.666. Nilai tersebut menunjukan bahwa sebesar $66 \%$ variabel keunggulan kompetitif dipengaruhi oleh green intellectual capital (GIC) dan green human resource management (GHRM), sedangkan sisanya dipengaruhi oleh variabel lain diluar variabel tersebut. Nilai $\mathrm{R}^{2}$ tersebut juga menandakan bahwa model dalam penelitian ini termasuk pada kriteria moderat menurut Hair et al (2011).

Quality Index

Untuk mengetahui index GoF (Goodness of Fit), PLS path modelling dapat mengidentifikasi kriteria global optimization. GoF index dikembangkan oleh Tenenhaus et al (2004) untuk mengevaluasi model pengukuran dan model structural (Ghozali \& latan, 2015). GoF dapat diukur menggunakan $\mathrm{Q}^{2}$ Predictive Relevance.

$$
\begin{aligned}
Q^{2} & =1-\left(1-R_{1}^{2}\right)\left(1-R_{2}^{2}\right) \\
& =1-(1-0.666)(1-0.464) \\
& =1-(0.334)(0.536) \\
& =1-0.179 \\
& =0.821
\end{aligned}
$$

Berdasarkan hasil hitung diatas, dapat dilihat bahwa perolehan nilai $\mathrm{Q}^{2}=0.821$. Hasil tersebut menunjukan bahwa keberagaman dari data penelitian yang dijelaskan oleh model sebesar $82 \%$, sedangkan sisanya dijelaskan oleh faktor lain diluar model penelitian. Karena nilai $\mathrm{Q}^{2}$ lebih mendekati 1, maka model dapat dikatakan baik. Menurut kriteria penilaian GoF, hasil tersebut menunjukan bahwa model penelitian ini termasuk dalam GoF Large. 


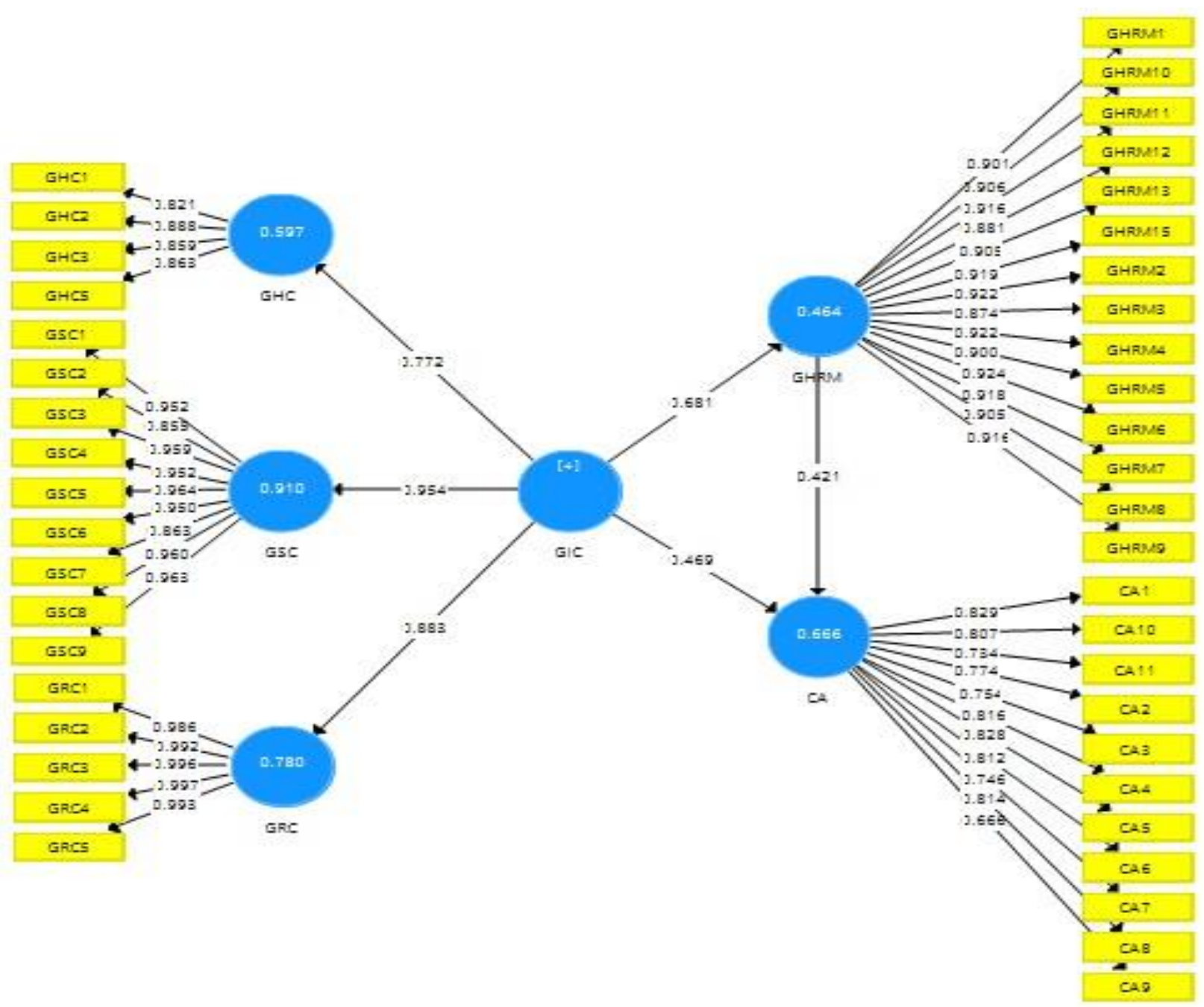

Gambar.1 Hasil Pengukuran Outer Model

Tabel.1 Nilai Loading Faktor

\begin{tabular}{|l|l|l|l|l|}
\hline \multicolumn{1}{|c|}{ First Order } & \multicolumn{1}{|c|}{ Second Order } & \multicolumn{1}{c|}{ Item } & Loading & \multicolumn{1}{c|}{ Ket } \\
\hline Green Human Capital & & GHC1 & 0.821 & Valid \\
\hline & & GHC2 & 0.888 & Valid \\
\hline & & GHC3 & 0.859 & Valid \\
\hline & & GHC5 & 0.863 & Valid \\
\hline Green Structural Capital & & GSC1 & 0.952 & Valid \\
\hline & & GSC2 & 0.855 & Valid \\
\hline & & GSC3 & 0.959 & Valid \\
\hline & & GSC4 & 0.952 & Valid \\
\hline & & GSC5 & 0.964 & Valid \\
\hline & & GSC6 & 0.95 & Valid \\
\hline & & GSC7 & 0.863 & Valid \\
\hline & & GSC8 & 0.96 & Valid \\
\hline
\end{tabular}




\begin{tabular}{|c|c|c|c|c|}
\hline First Order & Second Order & Item & Loading & Ket \\
\hline & & GSC9 & 0.963 & Valid \\
\hline \multirow[t]{8}{*}{ Green Relational Capital } & & GRC1 & 0.986 & Valid \\
\hline & & GRC2 & 0.992 & Valid \\
\hline & & GRC3 & 0.996 & Valid \\
\hline & & GRC4 & 0.997 & Valid \\
\hline & & GRC5 & 0.993 & Valid \\
\hline & \multirow{2}{*}{$\begin{array}{l}\text { Green Intellectual } \\
\text { Capital }\end{array}$} & Green Human Capital & 0.772 & Valid \\
\hline & & Green Structural Capital & 0.954 & Valid \\
\hline & & Green Relational Capital & 0.883 & Valid \\
\hline \multirow{14}{*}{$\begin{array}{l}\text { Green Human Resource } \\
\text { Management }\end{array}$} & & GHRM1 & 0.901 & Valid \\
\hline & & GHRM2 & 0.922 & Valid \\
\hline & & GHRM3 & 0.874 & Valid \\
\hline & & GHRM4 & 0.922 & Valid \\
\hline & & GHRM5 & 0.9 & Valid \\
\hline & & GHRM6 & 0.924 & Valid \\
\hline & & GHRM7 & 0.918 & Valid \\
\hline & & GHRM8 & 0.905 & Valid \\
\hline & & GHRM9 & 0.916 & Valid \\
\hline & & GHRM10 & 0.906 & Valid \\
\hline & & GHRM11 & 0.916 & Valid \\
\hline & & GHRM12 & 0.881 & Valid \\
\hline & & GHRM13 & 0.905 & Valid \\
\hline & & GHRM15 & 0.919 & Valid \\
\hline \multirow[t]{11}{*}{ Keunggulan Kompetitif } & & CA1 & 0.829 & Valid \\
\hline & & CA2 & 0.774 & Valid \\
\hline & & CA3 & 0.754 & Valid \\
\hline & & CA4 & 0.816 & Valid \\
\hline & & CA5 & 0.828 & Valid \\
\hline & & CA6 & 0.812 & Valid \\
\hline & & CA7 & 0.746 & Valid \\
\hline & & CA8 & 0.814 & Valid \\
\hline & & CA9 & 0.666 & Valid \\
\hline & & CA10 & 0.807 & Valid \\
\hline & & CA11 & 0.734 & Valid \\
\hline
\end{tabular}


Tabel 2. Nilai Cross Loading

\begin{tabular}{|c|c|c|c|c|c|c|}
\hline & GHC & GSC & GRC & GIC & GHRM & $\mathrm{CA}$ \\
\hline GHC1 & 0.821 & 0.489 & 0.526 & 0.626 & 0.5 & 0.706 \\
\hline GHC1 & 0.821 & 0.489 & 0.526 & 0.626 & 0.5 & 0.706 \\
\hline GHC2 & 0.888 & 0.569 & 0.512 & 0.68 & 0.655 & 0.711 \\
\hline GHC2 & 0.888 & 0.569 & 0.512 & 0.68 & 0.655 & 0.711 \\
\hline GHC3 & 0.859 & 0.578 & 0.482 & 0.667 & 0.53 & 0.625 \\
\hline GHC3 & 0.859 & 0.578 & 0.482 & 0.667 & 0.53 & 0.625 \\
\hline GHC5 & 0.863 & 0.59 & 0.486 & 0.677 & 0.541 & 0.662 \\
\hline GHC5 & 0.863 & 0.59 & 0.486 & 0.677 & 0.541 & 0.662 \\
\hline GSC1 & 0.607 & 0.952 & 0.711 & 0.906 & 0.602 & 0.656 \\
\hline GSC1 & 0.607 & 0.952 & 0.711 & 0.906 & 0.602 & 0.656 \\
\hline GSC2 & 0.591 & 0.855 & 0.686 & 0.84 & 0.538 & 0.606 \\
\hline GSC2 & 0.591 & 0.855 & 0.686 & 0.84 & 0.538 & 0.606 \\
\hline GSC3 & 0.613 & 0.959 & 0.697 & 0.906 & 0.588 & 0.598 \\
\hline GSC3 & 0.613 & 0.959 & 0.697 & 0.906 & 0.588 & 0.598 \\
\hline GSC4 & 0.594 & 0.952 & 0.704 & 0.901 & 0.591 & 0.643 \\
\hline GSC4 & 0.594 & 0.952 & 0.704 & 0.901 & 0.591 & 0.643 \\
\hline GSC5 & 0.624 & 0.964 & 0.693 & 0.91 & 0.596 & 0.609 \\
\hline GSC5 & 0.624 & 0.964 & 0.693 & 0.91 & 0.596 & 0.609 \\
\hline GSC6 & 0.581 & 0.95 & 0.707 & 0.899 & 0.583 & 0.631 \\
\hline GSC6 & 0.581 & 0.95 & 0.707 & 0.899 & 0.583 & 0.631 \\
\hline GSC7 & 0.628 & 0.863 & 0.697 & 0.856 & 0.567 & 0.642 \\
\hline GSC7 & 0.628 & 0.863 & 0.697 & 0.856 & 0.567 & 0.642 \\
\hline GSC8 & 0.601 & 0.96 & 0.69 & 0.902 & 0.578 & 0.586 \\
\hline GSC8 & 0.601 & 0.96 & 0.69 & 0.902 & 0.578 & 0.586 \\
\hline GSC9 & 0.636 & 0.963 & 0.7 & 0.914 & 0.606 & 0.621 \\
\hline GSC9 & 0.636 & 0.963 & 0.7 & 0.914 & 0.606 & 0.621 \\
\hline GRC1 & 0.577 & 0.738 & 0.986 & 0.873 & 0.548 & 0.626 \\
\hline GRC1 & 0.577 & 0.738 & 0.986 & 0.873 & 0.548 & 0.626 \\
\hline GRC2 & 0.588 & 0.737 & 0.992 & 0.876 & 0.578 & 0.64 \\
\hline GRC2 & 0.588 & 0.737 & 0.992 & 0.876 & 0.578 & 0.64 \\
\hline GRC3 & 0.58 & 0.746 & 0.996 & 0.881 & 0.566 & 0.634 \\
\hline GRC3 & 0.58 & 0.746 & 0.996 & 0.881 & 0.566 & 0.634 \\
\hline GRC4 & 0.582 & 0.744 & 0.997 & 0.881 & 0.574 & 0.638 \\
\hline GRC4 & 0.582 & 0.744 & 0.997 & 0.881 & 0.574 & 0.638 \\
\hline GRC5 & 0.571 & 0.74 & 0.993 & 0.875 & 0.572 & 0.641 \\
\hline GRC5 & 0.571 & 0.74 & 0.993 & 0.875 & 0.572 & 0.641 \\
\hline GHRM1 & 0.617 & 0.625 & 0.587 & 0.681 & 0.901 & 0.699 \\
\hline GHRM2 & 0.553 & 0.509 & 0.456 & 0.557 & 0.922 & 0.637 \\
\hline GHRM3 & 0.572 & 0.574 & 0.493 & 0.611 & 0.874 & 0.654 \\
\hline
\end{tabular}




\begin{tabular}{|l|r|r|r|r|r|r|}
\hline GHRM4 & 0.546 & 0.507 & 0.45 & 0.553 & $\mathbf{0 . 9 2 2}$ & 0.636 \\
\hline GHRM5 & 0.619 & 0.626 & 0.588 & 0.682 & $\mathbf{0 . 9}$ & 0.702 \\
\hline GHRM6 & 0.549 & 0.509 & 0.452 & 0.555 & $\mathbf{0 . 9 2 4}$ & 0.641 \\
\hline GHRM7 & 0.575 & 0.512 & 0.464 & 0.566 & $\mathbf{0 . 9 1 8}$ & 0.654 \\
\hline GHRM8 & 0.637 & 0.632 & 0.606 & 0.695 & $\mathbf{0 . 9 0 5}$ & 0.72 \\
\hline GHRM9 & 0.556 & 0.507 & 0.46 & 0.558 & $\mathbf{0 . 9 1 6}$ & 0.634 \\
\hline GHRM10 & 0.636 & 0.631 & 0.611 & 0.697 & $\mathbf{0 . 9 0 6}$ & 0.726 \\
\hline GHRM11 & 0.575 & 0.51 & 0.464 & 0.565 & $\mathbf{0 . 9 1 6}$ & 0.656 \\
\hline GHRM12 & 0.585 & 0.58 & 0.506 & 0.621 & $\mathbf{0 . 8 8 1}$ & 0.661 \\
\hline GHRM13 & 0.63 & 0.631 & 0.599 & 0.691 & $\mathbf{0 . 9 0 5}$ & 0.708 \\
\hline GHRM15 & 0.571 & 0.512 & 0.462 & 0.565 & $\mathbf{0 . 9 1 9}$ & 0.648 \\
\hline CA1 & 0.629 & 0.593 & 0.642 & 0.684 & 0.722 & $\mathbf{0 . 8 2 9}$ \\
\hline CA10 & 0.646 & 0.512 & 0.483 & 0.588 & 0.566 & $\mathbf{0 . 8 0 7}$ \\
\hline CA11 & 0.628 & 0.407 & 0.456 & 0.515 & 0.54 & $\mathbf{0 . 7 3 4}$ \\
\hline CA2 & 0.625 & 0.564 & 0.513 & 0.623 & 0.643 & $\mathbf{0 . 7 7 4}$ \\
\hline CA3 & 0.552 & 0.524 & 0.41 & 0.55 & 0.472 & $\mathbf{0 . 7 5 4}$ \\
\hline CA4 & 0.661 & 0.557 & 0.521 & 0.629 & 0.548 & $\mathbf{0 . 8 1 6}$ \\
\hline CA5 & 0.62 & 0.588 & 0.634 & 0.677 & 0.718 & $\mathbf{0 . 8 2 8}$ \\
\hline CA6 & 0.642 & 0.511 & 0.478 & 0.585 & 0.565 & $\mathbf{0 . 8 1 2}$ \\
\hline CA7 & 0.538 & 0.515 & 0.397 & 0.537 & 0.463 & $\mathbf{0 . 7 4 6}$ \\
\hline CA8 & 0.652 & 0.552 & 0.513 & 0.621 & 0.543 & $\mathbf{0 . 8 1 4}$ \\
\hline CA9 & 0.574 & 0.324 & 0.371 & 0.428 & 0.506 & $\mathbf{0 . 6 6 6}$ \\
\hline
\end{tabular}

Sumber: Data Primer diolah, 2020.

Tabel.3 Composite Reliability

\begin{tabular}{|c|c|c|c|c|}
\hline & Cronbach's Alpha & rho_A & $\begin{array}{l}\text { Composite } \\
\text { Reliability }\end{array}$ & (AVE) \\
\hline CA & 0.936 & 0.941 & 0.945 & 0.611 \\
\hline GHRM & 0.984 & 0.985 & 0.985 & 0.824 \\
\hline GIC & 0.975 & 0.976 & 0.978 & 0.71 \\
\hline GHC & 0.88 & 0.882 & 0.918 & 0.737 \\
\hline GRC & 0.996 & 0.996 & 0.997 & 0.986 \\
\hline GSC & 0.982 & 0.983 & 0.985 & 0.877 \\
\hline
\end{tabular}

Sumber: Data Primer diolah, 2020.

Tabel.4 R-Square $\left(\mathbf{R}^{2}\right)$

\begin{tabular}{|c|c|c|}
\hline & R Square & R Square Adjusted \\
\hline $\mathrm{CA}$ & 0.666 & 0.661 \\
\hline GHRM & 0.464 & 0.46 \\
\hline
\end{tabular}




\section{Uji Hipotesis (Bootstrapping)}

Tabel.5 Hasil Uji Hipotesis

\begin{tabular}{|c|l|r|r|r|r|r|}
\hline Hipotesis & & $\begin{array}{c}\text { Original } \\
\text { Sample } \\
(\mathrm{O})\end{array}$ & $\begin{array}{c}\text { Sample } \\
\text { Mean } \\
(\mathrm{M})\end{array}$ & $\begin{array}{c}\text { Standard } \\
\text { Deviation } \\
(\text { STDEV })\end{array}$ & $\begin{array}{c}\text { T Statistics } \\
(\mid \mathrm{O} / \mathrm{STDEV})\end{array}$ & \multicolumn{1}{c|}{$\begin{array}{c}\mathrm{P} \\
\text { Values }\end{array}$} \\
\hline $\mathrm{H}_{1}$ & $\begin{array}{l}\text { GIC } \rightarrow \\
\text { GHRM }\end{array}$ & 0.681 & 0.685 & 0.046 & 14.668 & 0.000 \\
\hline $\mathrm{H}_{2}$ & GHRM $\rightarrow \mathrm{CA}$ & 0.421 & 0.421 & 0.066 & 6.389 & 0.000 \\
\hline $\mathrm{H}_{3}$ & GIC $\rightarrow \mathrm{CA}$ & 0.469 & 0.471 & 0.066 & 7.104 & 0.000 \\
\hline $\mathrm{H}_{4}$ & $\begin{array}{l}\text { GIC } \rightarrow \\
\text { GHRM } \rightarrow \mathrm{CA}\end{array}$ & 0.287 & 0.288 & 0.047 & 6.106 & 0.000 \\
\hline
\end{tabular}

Sumber: Data Primer diolah, 2020

Berdasarkan tabel hasil uji hipotesis diatas (Tabel.5), dapat dilihat bahwa konstruk green intellectual capital terhadap green human resource management menunjukan nilai koefisien jalur (Original Sample) sebesar 0.618 dengan nilai T tatistik sebesar 14.668 dan nilai $\mathrm{P}$ Values $0.000<0.05$. Hasil tersebut menunjukan bahwa green intellectual capital berpengaruh positif signifikan terhadap green huan resource management. Untuk konstruk green human resource management terhadap keunggulan kompetitif, hasil menunjukan nilai koefisien jalur (Original Sample) sebesar 0.421 dengan nilai T tatistik sebesar 6.389 dan nilai $\mathrm{P}$ Values $0.000<0.05$. Hasil tersebut menunjukan bahwa green human resource management berpengaruh positif signifikan terhadap keunggulan kompetitif.sedangkan untuk konstruk green intellectual capital terhadap keunggulan kompetitif, hasil menunjukan nilai koefisien jalur (Original Sample) sebesar 0.469 dengan nilai T tatistik sebesar 7.104 dan nilai $\mathrm{P}$ Values $0.000<0.05$. Hasil tersebut menunjukan bahwa green intellectual capital berpengaruh positif signifikan terhadap keunggulan kompetitif.

\section{Pengujian Efek Mediasi}

Pada pengujian efek mediasi, hubungan antara variabel independent terhadap variabel dependen melalui variabel penghubung atau variabel antara akan dihitung menggunakan uji Sobel (Gozhali, 2011).

\section{Gambar 2. Diagram Jalur}

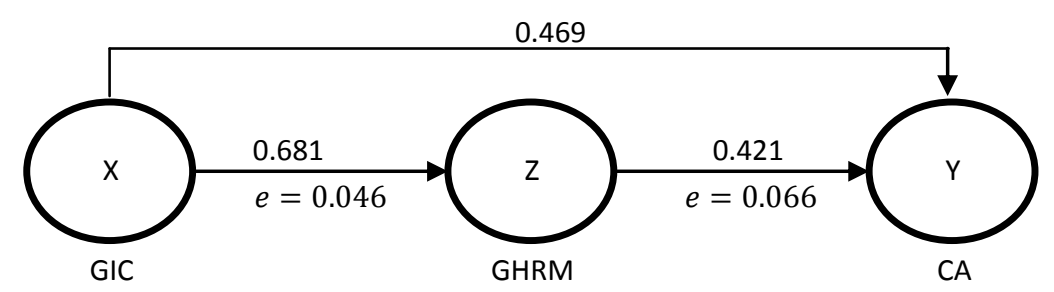

$$
t=\frac{a b}{\sqrt{b^{2} s a^{2}+a^{2} s b^{2}+s a^{2} s b^{2}}}
$$

Dengan:

a : pengaruh $\mathrm{X} \rightarrow \mathrm{Z}=$

0.681

$b \quad$ : pengaruh $\mathrm{Z} \rightarrow \mathrm{Y}=$ 


$=\frac{0.681 \times 0.421}{\sqrt{0.421^{2} 0.046^{2}+0.681^{2} 0.066^{2}+0.046^{2} 0.066^{2}}}$
$=\frac{0.287}{0.045}$
$=6.358 \mathrm{~m}$

0.421

$a b:$ perkalian antara pengaruh $\mathrm{X} \rightarrow \mathrm{Z}$ dengan $\mathrm{Z} \rightarrow \mathrm{Y}$

sa : standar error koefisien $\mathrm{a}=0.046$

$s b \quad:$ standar error koefisien $\mathrm{b}=0.066$

$s a b \quad$ : standar error pengaruh tidak langsung

Dari hasil perhitungan, didapatkan nilai t hitung $=6.358$ untuk pengaruh tidak langsung dari variabel green intellectual capital terhadap keunggulan kompetitif. Dari hasil tersebut dapat disimpulkan bahwa t hitung $=6.358>\mathrm{t}$ tabel $=2.613$. Maka Hipotesis 4 diterima. Sehingga, green human resource management dapat memediasi pengauh antara green intellectual capital terhadap keunggulan kompetitif

\section{Pembahasan}

Berdasarkan hasil uji, dapat disimpulkan bahwa green intellectual capital yang terdiri dari green human capital, green structural capital, dan green relational capital pada pemilik UKM di Paguyuban Batik Tulis Kebon Indah di Klaten memiliki pengaruh positif signifikan terhadap green human resource management paguyuban tersebut. Artinya, semakin tinggi modal intelektual tentang lingkungan yang dimiliki oleh paguyuban tersebut, maka manajemen SDM pada paguyuban semakin baik terkait dengan perlindungan lingkungan. Sebagaimana pandangan yang diberikan oleh Kong \& Thomson (2009) bahwa IC, HRM dan konsep HRM saling berhubungan erat (Yong, et al., 2019), hasil uji pada penelitian ini juga menunjukan bahwa GIC dan GHRM pada UKM Batik Tulis Kebon Indah memiliki hubungan yang erat. Hal ini digambarkan dengan pengaruh yang diberikan oleh GIC terhadap GHRM pada paguyuban tersebut yang mana hampir 50\% Green HRM pada paguyuban Batik Tulis Kebon Indah dipengaruhi oleh pengetahuan, kemampuan, dll tentang perlindungan lingkungan yang dimiliki oleh seluruh anggota paguyuban.

Pada analaisis deskriptif, rata-rata penilaian responden terhadap ketiga dimensi dari variabel GIC masuk dalam kriteria tinggi. Artinya, green intellectual capital yang dimiliki oleh Paguyuban Batik Tulis Kebon Indah termasuk tinggi. Dalam penelitian ini juga menunjukan bahwa dimensi yang paling besar dalam mencerminkan green intellectual capital pada paguyuban Batik Tulis Kebon Indah adalah green structural capital yaitu sebesar 95\%. Pada prakteknya, SDM yang dimiliki oleh Paguyuban Kebon indah sepenuhnya saling mengerti satu sama lain dan memahami peran sebagai anggota dan peran paguyuban dalam usahanya untuk mempertahankan produksi dan oprasionalnya agar tetap menggunakan bahan-bahan alam dan tidak meninggalkan jejak produksi yang dapat merusak lingkungan. Dutta (2014) mengatakan bahwa hal ini karena GHRM merupakan proses dalam menciptakan green workforce yang akan memahami dan menghargai budaya green dalam organisasi (Sheikh, et al., 2019) dan HRM merupakan alat yang ampuh untuk menyelaraskan anggota dengan strategi lingkungan yang dimiliki organisasi (Renwick, et al., 2013). Penelitian ini memberikan kesimpulan bahwa intellectual capital yang berorientasi pada lingkungan yang dimiliki Paguyuban, mulai dari green human capital, 
hubungan antar stakeholder, hingga hubungan Paguyuban dengan mitra, upstream dan downstream supplier, dapat membentuk management SDM yang berorientasi pada lingkungan pula. Semakin baik manajemen SDM tentang perlindungan lingkungan yang dimiliki oleh paguyuban, maka makin tinggi pula keunggulan paguyuban Batik Tulis Kebon Indah dalam berkompetisi.

Praktek GHRM dapat mempertahankan karyawan yang baik dalam organisasi, oleh karenanya komunitas bisnis banyak mengadopsi sistem manajemen lingkungan yang merupakan alat untuk memberikan keunggulan kompetitif (Rohilla, 2017). Industry batik yang saat ini telah menarik perhatian dunia menjadikan bisnis ini menjamur dan banyak diminati. Sehingga, paguyuban Batik Tulis Kebon Indah perlu untuk menjadikan anggotanya untuk tidak sekedar tahu, melainkan sadar dan perduli, seta memiliki passion dan pengetahuan terkait perlindungan lingkungan. Selain itu, penting juga untuk memahami tentang keuntungan yang dapat diperoleh dari menjaga kelestarian lingkungan untuk dapat bertahan dalam persaingan. GHRM merupakan alat stratejik yang dikembangkan organisasi bisnis, salah satunya untuk mendapatkan keunggulan bersaing (Aykan, 2017).

Batik Tulis Kebon Indah menunjukan pengaruh yang dapat dikatakan cukup besar dari GHRM yang dimilikinya untuk mendapatkan keunggulan berasing. Pada penelitian ini, keunggulan bersaing tidak diukur dari persaingan yang terjadi antar UKM di Paguyuban, namun diidentifikasi dari standar yang telah ditetapkan oleh paguyuban itu sendiri. Sebelumnya, banyak berdiri bisnis serupa di sekitar paguyuban. Namun, seiring berjalannya waktu, bisnis-bisnis tersebut tidak mampu menjaga strategi bersaing yang dimiliki, dari menggunakan bahan alam sepenuhnya, beberapa bisnis kemudian menambahkan bahan kimia, pada akhirnya bisnis-bisnis tersebut hilang satu persatu. Hal ini sudah cukup untuk membuktikan bahwa Paguyuban Batik Tulis Kebon Indah telah memiliki keunggulan dalam bersaing, salah satunya karena paguyuban memiliki HRM hijau sebagai alat kontrol untuk menjaga bisnis yang dilakukan agar tetap ramah lingkungan.

Hasil analisis menyimpulkan bahwa semakin baik GHRM yang dimiliki oleh sebuah organisasi, maka semakin tinggi kemampuan organisasi untuk dapat bertahan dalam persaingan, sehingga organisasi dapat tetap eksis dengan mendapatkan keunggulan kompetitif yang berkelanjutan. Hal ini dikarenakan GHRM berperan dalam internalisasi ideologi antara anggota dan staff agar tersedia sebuah perusahaan yang memiliki keunggulan bersaing (Zaid, et al., 2018), dan GHRM juga dapat memberikan keunggulan kompetitif baik melalui inovasi, maupun pengurangan biaya (Mishra, 2017). Berdasarkan hasil tersebut, dapat disimpulkan bahwa green intellectual capital yang terdiri dari green human capital, green structural capital, dan green relational capital pada pemilik UKM di Paguyuban Batik Tulis Kebon Indah di Klaten memiliki pengaruh langsung yang positif signifikan terhadap keunggulan kompetitif paguyuban tersebut. Artinya, semakin tinggi modal intelektual tentang lingkungan yang dimiliki oleh paguyuban tersebut, maka semakin tinggi pula kenunggulan kompetitif yang dimiliki. Dari analisis deskriptif yang menujukan bahwa pendapat responden terhadap GIC pada paguyuban tinggi, berarti anggota paguyuban memiliki green intellectual capital yang tinggi. Paguyuban juga dinilai dapat dan mampu mengembangkan dan menjaga produk ramah lingkungan dengan melakukan inovasi-inovasi, juga dengan menjaga hubungan baik dengan pelanggan, mitra, maupun dengan supplier tentang menjaga lingkungan. Dapat dikatakan bahwa paguyuban telah memiliki pengetahuan, kapabilitas karyawan, teknologi, pengalaman, dan kemampuan dalam mengimplementasi inovasi untuk mencapai tujuan organisasi (Huang \& Kung, 
2011). Hingga hari ini, paguyuban Batik Tulis Kebon Indah masih mampu bertahan tanpa mengubah strategi bisnisnya yang khusus menggunakan bahan alam, tanpa menurunkan atau mengurangi keuntungan yang didapat. Meskipun beberapa bisnis serupa yang pada awalnya berdiri bersama sama dengan paguyuban ini telah hilang satu persatu, GIC yang yang dimiliki paguyuban telah memberikan dampak positif dalam kemampuan paguyuban untuk mampu tetap bertahan sampai hari ini.

Hipotesis pada penelitian ini terbukti dari hasil pengujian konstruk yang menunjukan hasil koefisien jalur sebesar 0.287, nilai $\mathrm{T}$ statistic sebesar 6.106, dan diperkuat oleh pengujian efek mediasi menggunakan uji Sobel yang memberikan hasil perhitungan $\mathrm{T}$ hitung $6.358>\mathrm{T}$ tabel 2.613. Berdasarkan hasil tersebut, dapat disimpulkan bahwa pada Paguyuban Batik Tulis Kebon Indah di Klaten, green human resource management dapat memediasi pengaruh antara green intellectual capital dan keunggulan kompetitif. Pengaruh positif yang diberikan GIC terhadap GHRM, serta pengaruh positif yang diberikan oleh GHRM terhadap keunggulan kompetitif, menandakan bahwa GIC memiliki pengaruh tidak langsung terhadap keunggulan kompetitif, dan menandakan bahwa GHRM memiliki peran dalam memediasi pengaruh tersebut.

GHRM merupakan aspek terpenting dalam sebuah organisasi yang berperan dalam fungsi manajerial. HRM diperlukan untuk menjalankan aspek orang (Astuti \& Wahyuni, 2018). Peran GHRM sebagai alat control dalam organisasi sangat diperlukan untuk menjalankan strategi demi mencapai tujuan organisasi. SDM yang memiliki pengetahuan dan wawasan yang luas tentang lingkungan dan tujuan perusahaan, akan sangat membantu organisasi agar tetap pada strategi yang dijalankan sehingga dapat mencapai tujuan dan mampu unggul daam persaingan. Kesimpulannya, peran manajemen manusia dalam implementasi strategi lingkungan sangat penting bagi organisasi. hasil analisis menunjukan bahwa GHRM memiliki peran dalam memediasi. Kenyataannya, praktek training dan pengembangan, sistem reward, penilaian tertulis, dll, mempu meningkatkan dan mempertahankan pemahaman dan keperdulian anggota terhadap kelestarian lingkungan untuk mencapai green business. Artinya, semakin tinggi modal intelektual tentang lingkungan yang dimiliki oleh paguyuban tersebut, maka manajemen SDM pada paguyuban semakin baik terkait dengan perlindungan lingkungan serta akan memberikan keunggulan kompetitif yang semakin tinggi pula.

\section{KESIMPULAN}

Penelitian yang menggunakan data yang diambil dari 136 responden yang merupakan pemilik UKM batik warna alam di Paguyuban Kebon Indah, Klaten ini menunjukan bahwa green human resource management yang mencakup seluruh praktek HRM sebagai alat control dalam organisasi untuk menjalankan strategi perusahaan, memiliki peran dalam memediasi pengaruh green intellectual capital yang terdiri dari green human capital, green structural capital dan green relational capital terhadap keunggulan kompetitif. pada UKM batik warna alam di Paguyuban Kebon Indah. Peran yang dimiliki oleh GHRM ini ditunjukan oleh hasil perhitungan menggunakan uji Sobel yang menghasilkan nilai sebesar 6.358. Peran GHRM sebagai alat control pada organisasi sangat penting dalam mengimplementasi strategi lingkungan untuk mencapai tujuan organisasi, karna GHRM merupakan aspek yang berperan dalam fungsi manajerial untuk menjalankan aspek orang. GHRM mampu menciptakan green workforce yang akan menjaga strategi pada UKM batik warna alam di paguyuban Kebon Indah agar tetap memproduksi produk ramah lingkungan 
dengan menggunakan bahan alam sehingga tidak meninggalkan jejak produksi yang dapat merusak lingkungan. Green workforce ini juga berperan dalam mengontrol dan berinovasi secara terus menerus untuk memastikan bahwa organisasi selalu memiliki keunggulan dalam berkompetisi dengan tetap menjaga agar tetap mengarah pada tujuan organisasi.

\section{DAFTAR PUSTAKA}

Akbari, P., Rostami, R., \& Veismoradi, A. (2013). The analysis impact of Human Resource Management and Intellectual Capital on Organizational Performance in Physical Education Organization of Iran (Case Study: Physical Education General Department of Kermanshah). International journal of sport studies, 3(3), 263-273.

Andersson, L., Jackson, S. E., \& Russell, S. V. (2013). Greening organizational behavior: An introduction to the special issue. Journal of Organizational Behavior, 34(2), 151-155.

Arulrajah, A., Opatha, H., \& Nawaratne, N. (2015). Green Human Resource Management Practices: A Review. Sri Lankan Journal of Human Resource Management, 5(1), 116.

Astuti, M., \& Wahyuni, H. C. (2018). Strategi implementasi green human resource manajemen pasa usaha mikro, kecil, dan menengah (UMKM). Matrik : Jurnal Manajemen, Strategi Bisnis dan Kewirausahaan, 12(2), 121-128.

Aykan, E. (2017). Gaining a Competitive Advantage through Green Human Resource Management. Corporate Governance and Strategic Decision Making, 159-175.

Berry, M. A., \& Rondinelli, D. A. (1998). Proactive Corporate Environmental Management: A New Industrial Revolution. he Academy of Management Executive, 12(2), 38-50.

Budiarti, I. (2017). Knowledge Management and Intellectual Capital - A Theoretical Perspective of Human Resource Strategies and Practices. European journal of economic and business studies, 3(2).

Chalal, H., \& Bakshi, P. (2014). Effect of intellectual capital on competitive advantage and business performance: a role of innovation and learning culture. international journal of learning and intellectual capital, 11(1), 51-70.

Chang, C.-H., \& Chen, Y.-S. (2012). The determinants of green intellectual capital. Management Decision, 50(1), 74-94.

Chen, Y. S. (2008). The Positive Effect of Green Intellectual Capital on Competitive Advantages of Firms. Journal of Business Ethics, 77(3), 271-286.

Chen, Y.-S., \& Chang, C.-H. (2013). Enhance environmental commitments and green intangible assets toward green competitive advantage: an analysis of structural equation modeling (SEM). Quality \& Quantity, 47(1), 529-543.

Christmann, P. (2000). Effects of "Best Practices" of Environmental Management on Cost Advantage: The Role of Complementary Assets. The Academy of Management Journal, 43(4), 663-680.

Dutta, S. (2014). Greening People: A Strategic Dimension. ZENITH International Journal of Business Economics \& Management Research, 2(2), 143-148.

Ghozali, I. (2005). Aplikasi Analisis Multivariate dengan SPSS. Semarang: UNDIP.

Gozhali, I. (2011). Aplikasi analisis multivariate dengan program IBM SPSS 19 (5 ed.). Semarang: Badan penerbit Universitas Diponegoro. 
Gozhali, I. (2013). Aplikasi Analisis Multivariate dengan Program IBM SPSS 21. Semarang: Universitas Diponegoro.

Huang, C. L., \& Kung, F. H. (2011). Environmental consciousness and intellectual capital management: Evidence from Taiwan's manufacturing industry. Management Decision, 49(9), 1405-1425.

Jabbour, C. J. C., Santos, F. C. A., \& Nagano, M. S. (2010). Contribution of HRM Throughout the Stages of Environmental Management: Methodological Triangulation Applied to Companies in Brazil. International Journal of Human Resource Management, 21(7), 1049-1089

Jirawuttinunt, D. S. (2018). The Relationship between Green Human Resource Management and Green Intellectual Capital of Certified ISO 14000 Businesses in Thailand. St. Theresa Journal of Humanities and Social Sciences, 4(1), 20-37.

Khanna, M., \& Anton, W. R. (2002). Corporate Environmental Management: Regulatory and Market-Based Incentives. Land Economics, 78(4), 539-558.

Khatri, N. (2000). Managing Human Resource for Competitive Advantage: a study of companies in Singapore. The International Journal of Human Resource Management, 11(2), 336-365.

Kim, P. (2016). Green Business Trends and What to Expect. Dipetik Juli 16, 2019, dari https://www.smartcitiesdive.com/search/?q=Green+Business+Trends+and+What+to + Expect

Kong, E., \& Thomson, S. B. (2009). An intellectual capital perspective of human resource strategies and practices. Knowledge Management Research \& Practice , 7(4), 356364.

Kor, Y. Y. \& Mahoney, J. T., 2004. Edith Penrose's (1959) Contributions to the Resourcebased View of Strategic Management. Journal of Management Studies, 41(1), pp. 183-191.

Kramar, R., \& Mariappanadar, S. (2015). Call for papers for a Special Issue: Sustainable human resource management. Asia Pacific Journal of Human Resources, 53(3), 389-392.

Mandip, G. (2012). Green HRM: People Management Commitment to Environmental Sustainability. Research Journal of Recent Sciences , 1, 244-252.

Mazzi, A., Toniolo, S., Mason, M., Aguiari, F., \& Scipioni, A. (2016). What are the benefits and difficulties in adopting an environmental management system? The opinion of Italian organizations. Journal of Cleaner Production, 139, 873-885.

Mishra, P. (2017). Green human resource management: A framework for sustainable organizational development in an emerging economy. International Journal of Organizational Analysis, 25(5), 762-788.

mza/E-3. (2019, Febuari 14). Daelim Kembangkan Produk Ramah Lingkungan. Diambil kembali dari Koran Jakarta, (2018, April 12): http://www.koran-jakarta.com

Olander, H., Hurmelinna-Laukkanen, P., \& Heilmann, P. (2016). Human resources strength and weakness in protection of intellectual capital. Journal of intellectual capital, 16(4), 742-762.

Pinzone, M., Guerci, M., Lettieri, E., \& Redman, T. (2016). Progressing in the change journey towards sustainability in healthcare: the role of 'Green' HRM. Journal of Cleaner Production, 201-211. 
Porter, M. E., \& Kramer, M. R. (2006). Strategy and Society: The Link Between Competitive Advantage and Corporate Social Responsibility. Harvard Business Review, 84(12), 78-92.

Porter, M. E., (1995). Competitive Strategy: The Core Concepts. New york: The Free Press.

Porter, M. E., \& Linde, C. V. (1995). Green and Competitive. Harvard Business Review, 73(5), 120-134.

Renwick, D., Redman, T., Maguire, S. (2008). Green HRM: A review, process model, and research agenda. University of Sheffield Management School Discussion Paper, 1, 146. 0

Renwick, D. W., Jabbour, C. J., Muller-Camen, M., Redman, T., \& Wilkinson, A. (2012). Green human resource management:. The International Journal of Human Resource Management, 23(16), 3498-3499.

Renwick, D., Redman, T., \& Maguire, S. (2013). Green human resource management: a review, process model, and research agenda. International Journal of Management Reviews, 15(1), 1-14.

Rohilla, J. (2017). An Innovative Approach of Green Human Resource Management: Practices in the Organization. Global Journal for Research Analysis, 6(6), 174-176.

Sheikh, W., Islam, M. S., \& Rahman, F. (2019). Implementing Green Human Resource Management: Cost-Effective Strategies and Tools. Journal of Entrepreneurship Organization Management, 8(264).

Shrivastava, P. (1995). Environmental technologies and competitive advantage. Strategic Management Journal, 16(Special Issue), 183-200.

Shrivastava, P. (1995). The Role of Corporations in Achieving Ecological Sustainability. The Academy of Management Review, 20(4), 936-960.

Sudin, S. (2011). Strategic Green HRM: A proposed model that supports Corporate Environmental Citizenship. Singapore: IACSIT Press.

Sudin, S., \& Saad, Z. M. (2018). Linking Green HRM and Green Intellectual Capital with Corporate Environmental Citizenship Behaviour. Pahang, Malaysia: The European Proceedings of Social \& Behavioural Sciences.

Sugiyono. (2014). Metode Penelitian Bisnis. Bandung: Alfabeta.

Taylor, S., Osland, J., \& Egri, C. P. (2012). Guest editors' introduction: Introduction to HRM's role in sustainability: Systems, strategies, and practices. Human Resource Management, 51(6), 789-798.

Yong, J. Y., Yuliza, M. Y., Olawole, F., \& T, R. (2019). Nexus between green intellectual capital and green human resource management. Journal of Cleaner Production, 364-374.

Yusliza, M.-Y., Norazmi, N. A., Jabbour, C. J., Fernando, Y., Fawehinmi, O., \& Seles, B. M. (2019). Top management commitment, corporate social responsibility, and green human resource management. Brenchmarking: an international journal, 215(2019), 364-374.

Yusoff, Y. M., Omar, M. K., \& Kamarudin, M. D. (2019). Practice of green intellectual capital. Evidence from Malaysian manufacturing sector. Malaysia: IOP Conference Series: Materials Science and Engineering.

Zaid, A. A., Jaaron, A. A., \& Bon, A. T. (2018). The impact of green human resource management and green supply chain management practices on sustainable performance: an emperical study. journal of cleaner production, 204, 965-979. 